\title{
Non-Standard Employment and Wage Differences across Gender: a quantile regression approach
}

\author{
Anil Duman \\ Central European University \\ dumana@ceu.edu
}

\begin{abstract}
The paper aims to identify the effect of non-standard employment on wages in the Turkish labour market across gender and decompose the gap to understand the role of endowments and returns in generating the earning differences. Our findings show that non-standard employment reduces wages for women at every quantile but no such results are attained for men. Besides, females with standard jobs in Turkey earn more than men, however, the opposite holds for females in nonstandard positions. Also, a big part of the gender pay gap is attributable to returns, especially at the lower end of the distribution. Women in low-paid and atypical jobs face larger pay gaps, and the role of unexplained component suggests they are discriminated. The distinct impact of nonstandard employment on men and women suggest that policies geared towards labour market flexibilisation should take gender perspective into account.
\end{abstract}

JEL Classification: J31, J24, J41

Keywords: Non-standard employment, Gender pay gap, Quantile regressions, Recentered Influence Function (RIF), Decomposition, Discrimination 


\section{Introduction}

The pay differences between male and female employees remain to be a major issue in all countries and it is one of the biggest contributors to the gender inequalities. As a result, a large body of research is dedicated to analyzing the drivers of the gender wage gap within and across countries (Meurs and Ponthieux, 2015; Blau and Kahn, 2017). At the same time, non-standard employment (NSE) has been on the rise both in the developed and developing economies. NSE takes various forms such as part-time work, temporary contracts and self-employment in the advanced countries, in developing ones, a substantial amount of workers remain to be employed in the informal sector (ILO, 2016). There are numerous studies examining the implications of NSE for gender inequalities. For example, it is shown that women are disproportionately represented in part-time and fixed-term employment, and in many countries this is involuntary (Petrongolo, 2004). However, unlike part-time jobs, neither temporary nor informal employment is necessarily concentrated among women. With regards to the relationship between various types of NSE and wages, on the one hand, it is found that temporary contracts reduce the earnings of women in a number of European countries (Kahn, 2016). On the other hand, temporary agency work and casual employment are argued to increase the earnings for women, especially for the upper quantiles (Lass and Wooden, 2019). Given the similar gender composition of specific types of NSE and the mixed evidence regarding the female wages the impact of NSE on gender pay gap is still an empirically open question.

Our aim in this paper is, initially, to assess the effect of NSE on male and female wages, and then, decompose the pay gap to understand the reasons behind the gender differences among atypical $^{\mathrm{i}}$ workers. NSE is defined as jobs that are temporary, part-time or the informal sector. We claim that wage penalties for women in NSE would be higher as the already existing negative perceptions about female skills and productivity are coupled with limited legal protection in such jobs. Also, we argue that this form of inequity can differ along the distribution where low-paid workers are treated more unfavorably due to the interaction between gender perceptions and lower level of endowments. To this purpose, we look at the Turkish labor market, which has few distinguishing features such as relatively low gender wage gap among full-time employees, which is due to higher endowments. Also, labor force participation of low educated women is quite restricted, which suggest that there are few opportunities of paid work for this group. We contribute 
to the literature in several ways; first there are no studies looking at gender wage differences across employment types in Turkey. The findings can be illustrative for other emerging economies that have comparable gendered division in the labor markets. Additionally, we extend the discussion on the wage effects of NSE by empirically inspecting if females at the bottom of the distribution in atypical positions are more likely to be penalized than males.

The third contribution of the paper is the treatment of selection bias for labor force participation and employment type. Although, self-selection into labor force and its impact on gender wage differences are widely explored in the literature on wage gap, self-selection into distinct employment arrangements is less commonly investigated (Blau and Kahn, 2017; Bosio, 2014). Assuming that the working individuals as a random subgroup of the sample population can lead to incorrect results since active and inactive groups can differ systematically with regards to productivity, preferences and various other aspects. This is especially the case for Turkey where female labor force participation is noticeably lower than men and the disparity has been stagnant over time $^{\mathrm{ii}}$. Similarly, different individuals might opt for different employment types in labor markets contingent on their attributes and preferences. Hence, selection into NSE might be nonrandom, and peoples' unobserved characteristics are likely to play a role both in the determination of wages and employment type choices. We take both of these processes into accurately estimate gender pay gap and its decomposition. Nevertheless, the cross-sectional nature of our data doesn't allow us to account for the biases due to unobservables.

Our findings indicate that NSE reduces hourly wages for both genders; however, the magnitude is larger for women in Turkey. In addition, wage penalties not uniform across the distribution and both female and male employees at the bottom quantiles experience greater reductions due to atypical jobs. For men, there is even a small premium for NSE at the upper end of the distribution. These results highlight the disproportionate effects of atypical employment on female earnings, and suggest that employment type can be a contributing factor to the gender pay gap in Turkey, particularly for low wage groups. Our decompositions of wage differentials for standard and nonstandard employees strengthen these conclusions. Among standard workers in Turkey, women earn more than men at every quantile whereas the opposite findings are reached for non-standard workers. Female employees in NSE earn considerably less than their male counterparts along the distribution. Moreover, we find that the gap is especially large for the bottom end, and a considerable part of the wage difference between genders can be attributed to the unexplained 
component. This implies that low-paid female workers in atypical jobs experience further disadvantages in Turkish labor market as they receive lower returns to their human capital endowments.

In the reminder of the paper, we first briefly review theoretical and empirical literature on gender pay gap and its relationship to employment types. We also provide a brief background on Turkish labor market and the evolution of NSE across gender. The third part of the paper describes our data and empirical methodology. In the fourth part, we present our findings and discuss their implications. The fifth part offers concluding remarks along with limitations of our findings, and shortly discusses policies to address gender inequalities.

\section{Theoretical and Empirical Background}

Non-standard employment (NSE) is an umbrella term that is often used to describe jobs that offer limited social benefits and statutory entitlements due to contractual terms or lack of legal protections (ILO, 2016). Since for developing countries, informal sector employment is considerable, our definition of NSE includes informal sector workers along with part-time employees and temporary contract holders. In Turkey, a large proportion of temporary and parttime workers are involuntarily holding such contracts, and all informal workers are outside of social security coverage and employment protection legislation. Utilization of NSE became highly common both in developed and developing countries over the last decades. Standard employment relationships with full-time and permanent contracts have been largely replaced by temporary, part-time and agency work. Additionally, in developing countries, unregistered economic activities continue to be significant, putting a sizable part of workforce outside of the legal framework and social security protections. While a number of researchers argue that various benefits can accrue to employees in non-standard positions, such as better reconciliation of work and life and higher control over work schedules, it is shown that the positive effects are highly dependent on the context and atypical jobs, on average, have lower pay and less security (Booth et al., 2002; Gash and McGinnity, 2007; Cazes and de Laiglesia, 2015). Across a number of countries, large and persistent wage gaps exists between different types of contract holders (Duman, 2019; Garnero et al., 2016). Moreover, employees in precarious positions are subject to 
lower protection by labor legislation and union membership because of higher turnover and lack of integration of such workers into the collective bodies (Vosko et al., 2009; Grimshaw, 2011).

The rise of NSE across many countries led researchers to examine the impact of different forms of employment on gender inequalities. Although, human capital, work histories and occupational segregation are taken to be the primary factors behind the observed gender differences in labor markets, increasingly the variation of employment categories between men and women is considered to be relevant. For example, it has been found that part-time female employees receive lower wages even when they hold comparable endowments with their male peers (Garnero et al., 2016). Moreover, women are overrepresented in part-time jobs across Europe, and in Southern Europe such jobs are not voluntary, which noticeably reduces job satisfaction of female employees (Petrongolo, 2004). In terms of unemployment and occupational segregation, it is found that women are not necessarily more prone to holding temporary contracts in Germany. However, female employees at the beginning of their career are subject to higher risks of unemployment even when they have the same education with their male counterparts with fixed-term contracts (Kurz, 2002). With regards to wage effects of several types of NSE, sizable pay gaps across contract types in developed and developing countries are found, and it is shown that the earning differentials are not equal across genders (Duman, 2019; Cazes and de Laiglesia, 2015; Kahn, 2016; Gash and McGinnity, 2007). However, it should be noted that there is no agreement on the direction of the effect, as there are studies pointing out wage penalties as well as wage premiums for NSE, which also change along the distribution (Fuller and Vosko, 2008; Lass and Wooden, 2019).

We also argue that NSE has varied effects on wages across gender, and this cannot be fully attributed to the differences in endowments or greater representation of women in such jobs. It is well documented that human capital is losing its explanatory potential over time as women gain more education, but gender differences in occupations and industries continue to be an important determinant (Boll et al., 2017). Moreover, a big part of gender pay gap remains to be not fully explained by the observable characteristics, and can be attributed to discrimination (Blau and Kahn, 2017). Several forms of discrimination, including statistical discrimination as well as undervaluation of women's work due to gender norms, are identified in the literature that can affect gender composition of occupations as well as returns in the labor market. For example, correspondence tests found that women have lower chances of being interviewed for high-status 
jobs in traditional male occupations (Booth and Leigh, 2010; Duguet and Petit, 2005). Besides, employers might statistically discriminate female workers by considering the average performance rather than individual performance. Additionally, societal expectations with respect to genderspecific competences and skills affect the perceptions about productivity of women and hence their earnings (Meurs and Ponthieux, 2015).

With the exception of part-time jobs, other forms of NSE are not concentrated among women, which is also the case in Turkey as can be seen from Figure 1. For most years, the proportion of NSE across gender is quite comparable. Only after, 2012, the share of female employees in nonstandard jobs in Turkey began to marginally surpass the share of male employees. In 2017, these ratios were $23.4 \%$ and $19.5 \%$ for women and men respectively, and most of the decline of male NSE came from the reductions in informality ${ }^{\text {iii }}$ rather than changes in temporary contracts or parttime jobs (for regulatory changes over this period, see Duman, 2019; Duman, 2014). While NSE is not necessarily unevenly distributed between male and female employees in Turkey, there are important variations with regards to the characteristics of these jobs. It is asserted that non-standard positions are typically low paid and they include for the most part occupations requiring low and medium skills (Eichhorst and Marx, 2015). Hence, wage determination across employment categories can still be divergent and this divergence would have consequences for the gender pay gap.

Figure 1. Share of Non-Standard Employment across Gender (\%)

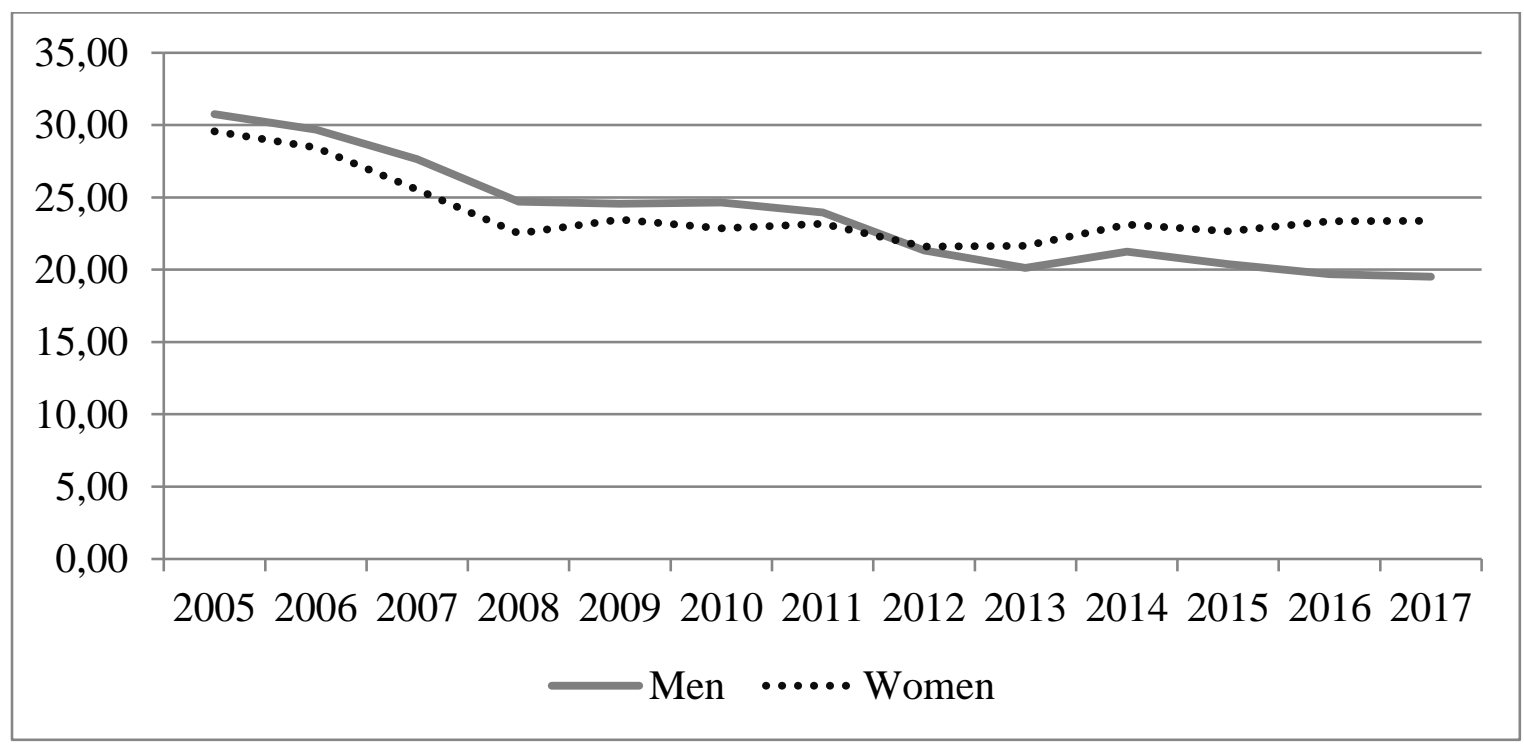

Source: Authors estimation based HLFS 
Turkish data supports the above propositions, which can be seen from the share of NSE across wage quartiles and gender in Figure 2. Atypical jobs are more widespread at the bottom end of distribution both for males and females but more so for the latter group. Approximately 59\% of low paid women have insecure jobs in Turkey whereas this ratio is $53 \%$ for men, and at upper quantiles, NSE is equally spread across genders; less than $4 \%$ for males and less than $3 \%$ for females at the top end of the distribution. Female employees with NSE in Turkey are subject to more adverse conditions in labor markets due to the coupling of already unfavorable gender norms and risks of atypical jobs. Obviously, women could experience discrimination in any type of employment but we propose that they are more likely to be subject to discriminatory practices in NSE because of limited legal and collective protection as well as undervaluation of female work and productivity (Grimshaw, 2011). The negative impacts are also expected to go up for the employees at the bottom end of wage distribution since bargaining power and exit options for women in low-paid and non-standard jobs are significantly poorer. Also, as can be observed from Figure 2, the share of NSE across wage quartiles in Turkey are considerably different, which indicates that looking at mean earnings would not be sufficient to understand the impact of employment types.

Figure 2. Share of Non-Standard Employment across Wage Quartiles and Gender (\%)

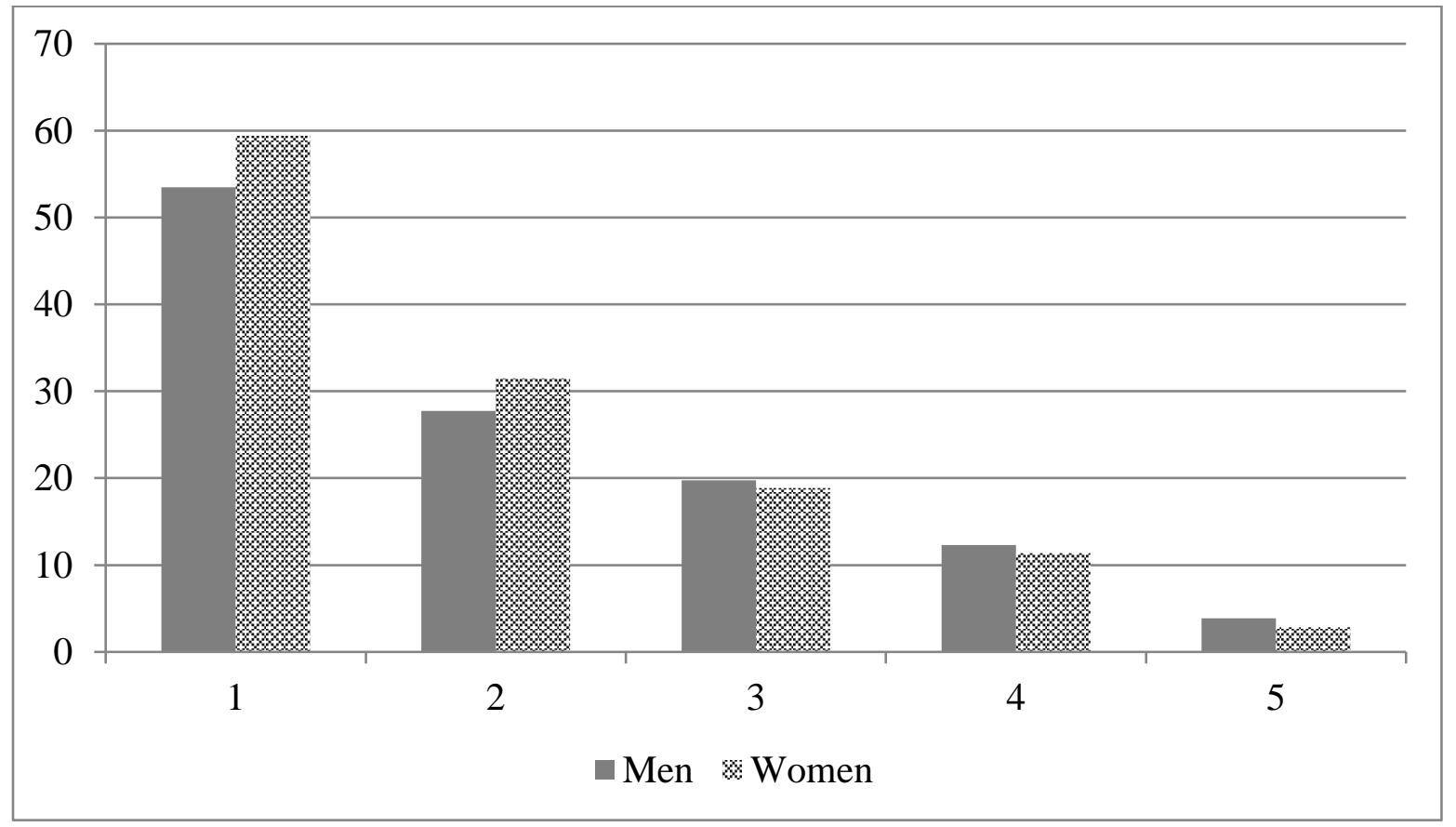

Source: Authors estimation based HLFS 
In the following parts of the paper we aim to identify the effect of NSE on wage determination for male and female workers in Turkey along the wage distribution. Also, we look at the decomposition of gender pay gap to understand the role of endowments and returns for standard and non-standard employees. There are few distinguishing features of Turkish labor market that can be helpful to extend our knowledge on gender wage gap. First, despite the low ranking of Turkey in terms of gender equality, the wage gap among full-time employees is estimated to be much lower than the OECD average (OECD, nd) ${ }^{\text {iv }}$. Our findings indicate that this is mainly an outcome of greater endowments women have, and as a result, they get better pay in permanent and formal sector jobs. Another distinguishing feature of the Turkish labor market is the low level of female participation rate, which is very unevenly distributed across educational categories. In 2018, labor force participation rate was $73.1 \%$ among university graduates whereas the same ratio was only $34.6 \%$ for women with primary schooling (TUIK, 2020). This, we argue, exacerbates the negative effects of NSE on female wages, especially for the bottom of the distribution as there are very few exit options for the unskilled women.

We build a large dataset from the Household Labour Force Surveys (HLFS) over the period of 2005 and 2017. The new dataset allows us to control for a long list of individual, firm, industrial and occupational variables that can affect gender pay gap. Additionally, we control for selection into labor force and NSE as both can be non-random and ultimately influence the wages. There are few studies on Turkey but most of them only examine the mean wage differences between men and women, and depending on the data source the results vary greatly. For example, the gap ranges from $4 \%$ in studies that consider the period before 2000s and use Household Income and Consumption Survey to 38\% that look at more recent years and Household Labour Force Survey (Ilkkaracan and Selim, 2007; Cudeville and Gurbuzer, 2010). In the few studies that investigate the gender pay gap along the wage distribution, it is found that women at the upper quantile earn 6-7.5\% less than men while there is no wage gap at the bottom end of the distribution after individual, firm and industrial level features are controlled for (Aktas and Uysal, 2016; Kaya, 2019). Nonetheless, the previous research doesn't assess the relationship between employment types and wages across gender in Turkey and doesn't decompose the gap to identify endowment and discrimination effects. 


\section{Data and Methodology}

\subsection{Data Description}

The main data source of this study is Household Labor Force Survey (HLFS) collected by the Turkish Statistical Institute ${ }^{\mathrm{v}}$. A pooled dataset is formed for the period between 2005 and 2017, which includes all the survey years that have a question on contract types. The survey annually covers nearly 150,000 households and 500,000 individuals reporting a long list of demographic and detailed labor market characteristics. In total, the pooled dataset has more than 6 million observations covering all the regions in Turkey. Since we are interested in the wage effect of NSE on male and female workers, we exclude unpaid family workers, self-employed individuals, and individuals stated as employers in the survey. For the hourly wages we divide the net monthly earnings ${ }^{\mathrm{vi}}$ by the total hours worked in a month. In the estimations we transform hourly wages to their natural logarithm and calculate the real wages for each year using consumer price index (CPI). These procedures left us with a total of 1,138,940 observations. Standard employment is defined as the permanent jobs in the formal sector whereas non-standard employment includes temporary, part-time and informal sector workers. The temporary workers ${ }^{\mathrm{vii}}$ are classified as anyone who is currently employed and has a non-permanent contract, which is derived from a direct question in the survey. The informality ${ }^{\text {viii }}$ in Turkey is captured by the question asking the respondents whether they are registered under the social security system or not. Similarly, part-time employment is derived directly from the question where participants report if they have a full-time job or not.

Table $1^{\text {ix }}$ presents the distribution of the key variables across genders for the wage workers in Turkey. Summary statistics for all the variables used in the estimations are shown in Table A1 of the Appendix. From the total 1,138,940 observations, $25.14 \%$ of the workers are in atypical jobs and there is no significant difference between male and female employees. Among them, 26.1\% of women are in non-standard employment and the ratio is $24.8 \%$ for men. Even though it is not possible to directly compare the share of non-standard employment across countries because of definitional issues, the ratios in Turkey are lower than the Latin American averages and at par with Southeastern European countries (ILO, 2016). With regards to age and education, it can be seen that female workers are slightly younger and a greater share of them have university degree. With respect to tenure, among men there is a higher share that has more than 10 years of experience in 
the job. For women, the majority, 63.3\% of the employees has tenure between 1 and 10 years and less than $18 \%$ of them have longer than 10 years.

Table 1. Share of Key Variables across Gender

\begin{tabular}{|l|l|l|}
\hline & Male & Female \\
\hline Contract Type & $24.8 \%$ & $26.1 \%$ \\
\hline Non-standard & $75.2 \%$ & $73.9 \%$ \\
\hline Standard & & \\
\hline Age & & \\
\hline $15-24$ old & $15.62 \%$ & $20.96 \%$ \\
\hline 25-55 old & $80.53 \%$ & $76.62 \%$ \\
\hline$>55$ old & $3.85 \%$ & $2.42 \%$ \\
\hline Education & & \\
\hline Less than primary & $3.29 \%$ & $5.99 \%$ \\
\hline Primary & $30.48 \%$ & $21.22 \%$ \\
\hline Secondary & $19.5 \%$ & $11.37 \%$ \\
\hline High & $25.69 \%$ & $23.15 \%$ \\
\hline University and higher & $21.04 \%$ & $38.27 \%$ \\
\hline Tenure (Number of Years in the Job) & & \\
\hline Less than 1 years & $18.57 \%$ & $18.99 \%$ \\
\hline $1-10$ years & $57.05 \%$ & $63.30 \%$ \\
\hline More than 10 years & $24.38 \%$ & $17.71 \%$ \\
\hline Firm size (Number of Employees in the Firm) & & \\
\hline$<10$ employees & $35.07 \%$ & $31.69 \%$ \\
\hline $10-50$ employees & $36.96 \%$ & $39.66 \%$ \\
\hline$>50$ employees & $27.97 \%$ & $28.65 \%$ \\
\hline Source: Auhor's calcutios based & \\
\hline
\end{tabular}

Source: Author's calculations based on Household Labor Force Statistics (2005-17).

In standard employment the mean hourly wage for men is 7.46 TL for men and 8.4 TL for women. When we look at the mean hourly wages for each gender in non-standard employment, they are found to be 3.46 TL for the male and 3.2 TL for the female workers in Turkey. These numbers hint at the fact that atypical jobs, regardless of gender, decrease the payments but women are still penalized more. In Figure A1 in the Appendix, the distribution of hourly wages for nonstandard employees is displayed, which hint at the differences in male and female pay in NSE. Figure 3 presents the raw hourly wages across five quartiles and it appears that decrease in mean wages is not uniform across the distribution, which is in line with our argument that women in 
NSE at the bottom are penalized more. The raw hourly earnings gap across genders is around 0.22 $\mathrm{TL}$ for the $1^{\text {st }}$ quartile but the gap gets smaller for the upper quartile, it is $0.04 \mathrm{TL}$. These correspond to almost $35 \mathrm{TL}$ difference per month for full-time employees at the $1^{\text {st }}$ quartile and less than $7 \mathrm{TL}$ difference at the $5^{\text {th }}$ quartile. Even though these figures don't take individual and firm level characteristics into account, they imply that rates of penalty for non-standard employment vary not only across genders but also across the distribution. In the following sections, unconditional quantile regression method and corresponding decomposition technique are used to filter out the effects of several variables and estimate the correct wage gap across genders with varied employment arrangements.

Figure 3. Raw Hourly Male-Female Wage Differences (TL)

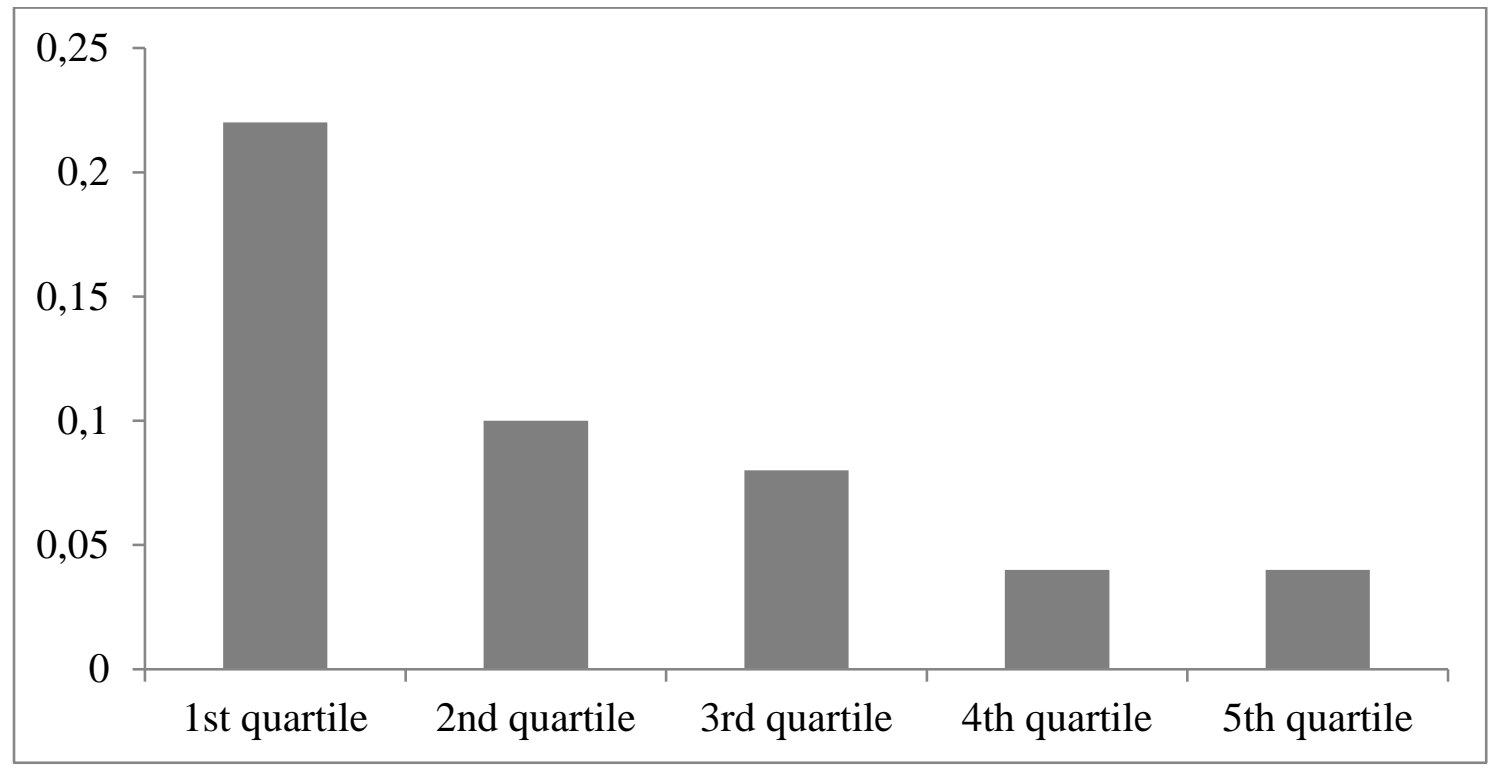

Source: Authors estimation based HLFS

\subsection{Empirical Strategy}

A number of studies in the literature examined the pay gap between types of NSE and standard workers as well as across genders by using a standard Mincerian framework where the wage is determined by a number of covariates such as human capital and firm characteristics. However, as discussed earlier, neither the gender pay gap nor the impact of non-standard employment on wages are uniform across the distribution. Therefore, we employ quantile regression techniques, which 
take the same base model and estimate the impact of atypical jobs and other covariates over the wage distribution. But the standard QR models are conditional, which means that the relationship between dependent and explanatory variables can only be examined by looking at a specific distribution of the dependent variable. In order to obtain unconditional effects we use unconditional quantile regression (UQR). This method allows us to see how unconditional expectation of the dependent variable changes when unconditional distribution of the explanatory variable changes (Firpo et al., 2009). Since we are interested in how non-standard employment affects hourly wages for men and women, it is more useful to assume no conditionality on the distribution.

UQR is based on extending the concept of influence function (IF), which is commonly employed as tool for robust estimation that can easily be computed for each quantile of interest. Firpo et al. (2009) add $v\left(F_{Y}\right)$ to IF in order to reach the recentered influence function (RIF), and show that RIF has the same properties with IF. Hence, they can be used to calculate the standard errors of any statistic for which RIF exists. In sum RIF for a given quantile can be taken as a linear approximation of the nonlinear function of the quantile, and captures the change of the unconditional quantile of the outcome in response to a change in the underlying distribution of the covariates (Firpo et al., 2009; Fortin et al., 2011). The estimation of RIF regressions under the linearity assumption enables us to interpret the coefficients similar to OLS, as the effect of a change in the mean of an explanatory variable in respective quantiles. We compute the unconditional quantile partial effects based on RIF, and analyze the impact of non-standard jobs on wages along the unconditional wage distribution by specifying the following linear UQR for selected quantiles of the unconditional distribution of real hourly wages $\left(\mathrm{q}_{\pi}\right)$ :

$$
\mathrm{RIF}\left(\ln \left(\mathrm{w}_{\mathrm{i}}\right), \mathrm{q}_{\pi}\right)=\mathrm{q}_{\pi}+\mathrm{IF}\left(\ln \left(\mathrm{w}_{\mathrm{i}}\right), \mathrm{q}_{\pi}\right)=\mathrm{q}_{\pi}+\frac{\left.\pi-I\left(\ln w_{i}\right) \leq q_{\pi}\right)}{f \ln (w)^{q_{\pi}}}
$$

By replacing the unknown components with their sample estimators in Equation (1) gives us the estimated RIF:

$$
\begin{aligned}
& \left.\overline{R I F}\left(\ln \left(\mathrm{w}_{\mathrm{i}}\right), \overline{q_{\pi}}\right)=\overline{q_{\pi}}\right)+\overline{I F}\left(\ln \left(\mathrm{w}_{\mathrm{i}}\right), \overline{q_{\pi}}\right)=\overline{q_{\pi}}+\frac{\left.\pi-I\left(\ln w_{i}\right) \leq \overline{q_{\pi}}\right)}{\bar{f} \ln (w)^{\bar{q} \pi_{\pi}}} \\
& E\left[\overline{R I F}\left(\ln \left(w_{i}\right), \overline{q_{\pi}}\right) \mid X_{i}, N S E_{i}\right\rfloor=\bar{\sigma}_{\pi}+\overline{\beta_{\pi}^{\prime}} X_{i}+\sum \overline{\delta_{\jmath \pi}} I\left(N S E_{i=j}\right) \mathrm{j}=1 \ldots \mathrm{J}-1
\end{aligned}
$$


where $X_{i}$ is the vector of covariates and $N S E_{i}$ is the employment type.

We also consider sample selection bias in our estimations. Both labor force participation and non-standard employment can be subject to selection bias, which can affect the gender wage gap. In order to correct these, we estimate two different probit equations and include the calculated inverse Mill's ratios in the UQR equations ${ }^{\mathrm{x}}$. To reach the inverse Mill's ratios, the paper utilizes a similar approach to Heckman's (1979) two step procedure, which is later revised by Buchinsky (1998) to be suitable for quantile estimation techniques. According to this method, the control functions of the propensity score in the quantile regressions can be controlled to correct for the sample selection for additive models with independent errors. Given that RIF estimations have these properties, we use the two-step approach proposed by Buchinksy (1998). In the first step, the probability of individuals participating in the labor force and the probability of workers to be in non-standard jobs is estimated by the following equations:

$$
\begin{gathered}
L F P^{*}=Z_{i}^{\prime} \gamma+u_{i} \\
N S C^{*}=B_{i}^{\prime} \mu+v_{i}
\end{gathered}
$$

where $L F P^{*}$ and $N S C^{*}$ are latent variables, $Z$ and $B$ are the vectors of explanatory variables, $\gamma$ and $\mu$ are the coefficients to be estimated and $u_{i}$ and $v_{i}$ are the error terms for labor force participation and type of employment.

The exclusionary variable in $Z$ vector is the number of children under the age of six in the household. Women who have young children that need care are expected to have lower probability of entering into labor market. This is one of the most widely used variables in the literature to correct for the selection bias in labor force participation (Heim, 2007; Blau and Kahn, 2017). B vector includes a variable based on the question in the survey about job searching. If the person is employed and looking for a job, the dummy variable gets a value of 1 and 0 otherwise. This variable is constructed with the idea that workers in non-standard employment are more likely to be searching for jobs in comparison to workers with permanent contracts in the formal sector, which is the reference category. It has been also utilized in several other studies examining the wage gap across contract types (Picchio 2006; Bosio 2014). It should be noted that the selfselection correction by Heckman's model depends on the strength of exclusion variable and 
accurate standard error estimation in the second stage. While we ensure that the standard errors are corrected through bootstrapping, the choice of exclusionary variables is restricted due to data availability.

Once we estimate the UQR coefficients we decompose the differences at selected quantiles of the wage distribution between two groups of workers. Firpo et al. (2009) show that a corresponding Oaxaca-Blinder decomposition can be approximated for quantiles, and the method is based on two stages. First, we split the distributional changes into the composition (endowment) and wage structure (discrimination) effects. The first component looks at the portion of wage gap between men and women that can be ascribed to the observable individual and firm-level attributes such as gender, age, education, experience, firm size, full-time position, and social security. The second component focuses on the wage gap arising due to the returns on these characteristics and to what extent one group is treated more favorably in the labor market. While the reward effect is generally understood as a measure of labor market discrimination, it indeed measures the unexplained component in wage differentials. In order to decompose the gender wage gap into these two parts, we generate a counterfactual wage distribution; distribution of the wages of female employees if they had the same distribution of characteristics as male employees. In the second stage of the decomposition exercise, we run separate RIF regressions for female, male and counterfactual wage distributions. Finally, we distinguish the gender wage gap into explained (endowment effect) and unexplained components (discrimination effect) at each quantile. The estimation equation becomes:

$$
\begin{aligned}
& \bar{q}_{M \pi}-\overline{q_{F \pi}}=\overline{R I F}\left(\ln \left(w_{M}\right), \overline{q_{\pi}}\right)-\overline{R I F}\left(\ln \left(w_{F}\right), \overline{q_{\pi}}\right)= \\
& \left(\overline{X_{M}}-\overline{X_{F}}\right) \overline{\beta_{\pi}}+\left[\left(\overline{X_{M}}\left(\overline{\beta_{M \pi}}-\overline{\beta_{\pi}}\right)+\left(\overline{\alpha_{M \pi}}-\overline{\alpha_{\pi}}\right)\right)+\left(\overline{X_{F}}\left(\overline{\beta_{F \pi}}-\overline{\beta_{M}}\right)+\left(\overline{\alpha_{F \pi}}-\overline{\alpha_{\pi}}\right)\right)\right]
\end{aligned}
$$

$\beta_{\pi}$ is the non-discriminatory wage structure that is estimated from a pooled RIF regression at quantile $\pi .=\left(\overline{X_{M}}-\overline{X_{F}}\right) \overline{\beta_{\pi}}$ captures the endowment effect and $\left(\overline{X_{M}}\left(\overline{\beta_{M \pi}}-\overline{\beta_{\pi}}\right)+\left(\overline{\alpha_{M \pi}}-\right.\right.$ $\left.\left.\overline{\alpha_{\pi}}\right)\right)+\left(\overline{X_{F}}\left(\overline{\beta_{F \pi}}-\overline{\beta_{M}}\right)+\left(\overline{\alpha_{F \pi}}-\overline{\alpha_{\pi}}\right)\right)$ captures the returns to these endowments. 


\section{Findings}

Table 2 and 3 present the UQR regression results over five quantiles for male and female employees separately. Before we move on to the impact of non-standard employment on wages across gender, we briefly discuss the control variables. First of all, it should be noted that while the selection term for labor force participation has a significant coefficient, selection term for nonstandard employment is not statistically explanatory across genders and quantiles ${ }^{\mathrm{xi}}$. This can be due to the low female labor force, especially among the unskilled, in Turkey. As can be seen from both samples, belonging to the prime working age group, having longer years of schooling, being experienced and working in a larger firm increase hourly wages, which are in line with the previous studies in the literature (Meurs and Ponthieux, 2015). The coefficients are stable across the distribution but particularly university education, tenure and firm size have larger effects on wages towards the upper end for men and women. For example, being a university graduate increases wages by $13 \%$ for the bottom quantile and $60 \%$ for the top one. Similarly, working in a firm with more than 50 employees raises the real hourly wages by $12 \%$ at the lower and $26 \%$ at the upper end of the distribution.

When we look at the coefficient on NSE, it can be seen that for men a large and negative relationship exists for the $10^{\text {th }}$ quantile but the impact gets smaller over the distribution and turns into a positive one at the $90^{\text {th }}$ quantile. Having non-standard job reduces hourly wages for male employees by $30 \%$ at the bottom and increases it by $2 \%$ at the top of the distribution. Wage premium for non-standard employment can be the due to compensation since firms could be willing to pay more to the skilled and productive individuals with less favourable working conditions such as job security (Garnero et al., 2016). However, as can be observed from Table 3 below, all female workers in Turkey are subject to wage penalties in case of non-standard employment. The negative and significant effects on hourly wages exist along the distribution unlike their male counterparts. At the bottom quantile, the earnings decline nearly by $45 \%$ and even though the impact gets smaller, still there is $6 \%$ wage penalty at the top of the distribution. These findings are robust to different specifications and sample sizes; hence it can be argued that employment types affect wages distinctively across genders in Turkey. Table A1 and A2 in the Appendix provide the results from the estimations for robustness checks ${ }^{\mathrm{xii}}$. 
Table 2. Effect of Non-Standard Employment on Male Wages

\begin{tabular}{|c|c|c|c|c|c|}
\hline & 10th & 25th & 50th & 75th & 90th \\
\hline NSE & $\begin{array}{c}-0.30^{* * *} \\
(0.00)\end{array}$ & $\begin{array}{c}-0.18^{* * *} \\
(0.00)\end{array}$ & $\begin{array}{l}-0.1^{* *} \\
(0.00)\end{array}$ & $\begin{array}{c}-0.05^{* * *} \\
(0.00)\end{array}$ & $\begin{array}{c}0.02 * * \\
(0.00)\end{array}$ \\
\hline 25-55 years & $\begin{array}{c}0.23 * * \\
(0.00)\end{array}$ & $\begin{array}{c}0.19^{* *} \\
(0.00)\end{array}$ & $\begin{array}{l}0.2^{* *} \\
(0.00)\end{array}$ & $\begin{array}{c}0.14 * * \\
(0.00)\end{array}$ & $\begin{array}{l}0.03 * * \\
(0.00)\end{array}$ \\
\hline$>55$ years & $\begin{array}{c}0.18^{* * *} \\
(0.00)\end{array}$ & $\begin{array}{c}0.14 * * \\
(0.00)\end{array}$ & $\begin{array}{l}0.15 * * \\
(0.00)\end{array}$ & $\begin{array}{l}0.14 * * \\
(0.00)\end{array}$ & $\begin{array}{l}0.08 * * \\
(0.00)\end{array}$ \\
\hline Primary school & $\begin{array}{c}0.09 * * \\
(0.00)\end{array}$ & $\begin{array}{c}0.03 * * \\
(0.00)\end{array}$ & $\begin{array}{l}0.03 * * \\
(0.00)\end{array}$ & $\begin{array}{c}-0.04 * * \\
(0.00)\end{array}$ & $\begin{array}{c}-0.03^{* *} \\
(0.00)\end{array}$ \\
\hline Secondary school & $\begin{array}{c}0.05^{* *} \\
(0.00)\end{array}$ & $\begin{array}{c}0.04 * * \\
(0.00)\end{array}$ & $\begin{array}{l}0.06^{* * *} \\
(0.00)\end{array}$ & $\begin{array}{l}0.05^{* *} \\
(0.00)\end{array}$ & $\begin{array}{c}-0.02 * * \\
(0.00)\end{array}$ \\
\hline High school & $\begin{array}{l}0.13 * * \\
(0.00)\end{array}$ & $\begin{array}{c}0.11 * * \\
(0.00)\end{array}$ & $\begin{array}{l}0.15^{* *} \\
(0.00)\end{array}$ & $\begin{array}{l}0.16^{* * *} \\
(0.00)\end{array}$ & $\begin{array}{c}0.006^{* *} \\
(0.00)\end{array}$ \\
\hline University and above & $\begin{array}{c}0.13 * * \\
(0.00)\end{array}$ & $\begin{array}{c}0.14 * * \\
(0.00)\end{array}$ & $\begin{array}{c}0.27 * * \\
(0.00)\end{array}$ & $\begin{array}{l}0.72 * * \\
(0.00)\end{array}$ & $\begin{array}{l}0.6^{* * *} \\
(0.00)\end{array}$ \\
\hline $1-10$ years of tenure & $\begin{array}{c}-0.06^{* * *} \\
(0.00)\end{array}$ & $\begin{array}{c}-0.03^{* * *} \\
(0.00)\end{array}$ & $\begin{array}{c}-0.03 * * \\
(0.00)\end{array}$ & $\begin{array}{c}0.03^{* *} \\
(0.00)\end{array}$ & $\begin{array}{l}0.02 * * \\
(0.00)\end{array}$ \\
\hline$>10$ years of tenure & $\begin{array}{c}-0.04 * * \\
(0.00)\end{array}$ & $\begin{array}{c}0.04 * * \\
(0.00)\end{array}$ & $\begin{array}{c}0.18^{* * *} \\
(0.00)\end{array}$ & $\begin{array}{l}0.6^{* *} \\
(0.00)\end{array}$ & $\begin{array}{l}0.31 * * \\
(0.00)\end{array}$ \\
\hline 10-50 employees & $\begin{array}{l}0.12 * * \\
(0.00)\end{array}$ & $\begin{array}{c}0.11 * * \\
(0.00)\end{array}$ & $\begin{array}{l}0.11 * * \\
(0.00)\end{array}$ & $\begin{array}{l}0.12 * * \\
(0.00)\end{array}$ & $\begin{array}{l}0.06^{* * *} \\
(0.00)\end{array}$ \\
\hline$>50$ employees & $\begin{array}{l}0.12 * * \\
(0.00)\end{array}$ & $\begin{array}{c}0.14 * * \\
(0.00)\end{array}$ & $\begin{array}{c}0.18 * * \\
(0.00)\end{array}$ & $\begin{array}{l}0.28 * * \\
(0.00)\end{array}$ & $\begin{array}{c}0.26 * * \\
(0.00)\end{array}$ \\
\hline NSE Selection Term & $\begin{array}{l}-0.01 \\
(0.02)\end{array}$ & $\begin{array}{l}-0.02 \\
(0.01)\end{array}$ & $\begin{array}{c}-0.05 * * \\
(0.01)\end{array}$ & $\begin{array}{l}-0.1 * * \\
(0.02)\end{array}$ & $\begin{array}{l}-0.06^{*} \\
(0.02)\end{array}$ \\
\hline LFP Selection Term & $\begin{array}{l}0.61 * * \\
(0.02)\end{array}$ & $\begin{array}{c}0.37 * * \\
(0.01)\end{array}$ & $\begin{array}{l}0.31 * * \\
(0.01)\end{array}$ & $\begin{array}{l}0.42 * * \\
(0.02)\end{array}$ & $\begin{array}{l}0.18^{* *} \\
(0.01)\end{array}$ \\
\hline Industry & Yes & Yes & Yes & Yes & Yes \\
\hline Occupation & Yes & Yes & Yes & Yes & Yes \\
\hline Region & Yes & Yes & Yes & Yes & Yes \\
\hline Year & Yes & Yes & Yes & Yes & Yes \\
\hline No of obs. & 852,356 & 852,356 & 852,356 & 852,356 & 852,356 \\
\hline R-Square & 0.24 & 0.32 & 0.42 & 0.5 & 0.36 \\
\hline
\end{tabular}

Notes: The reference category is standard employment. UQR models are estimated with bootstrapped standard errors. ** and $*$ denote statistical significance at the .01 and .05 levels, respectively. 
Table 3. Effect of Non-Standard Employment on Female Wages

\begin{tabular}{|l|c|c|c|c|c|}
\hline & $\mathbf{1 0 t h}$ & $\mathbf{2 5 t h}$ & $\mathbf{5 0 t h}$ & $\mathbf{7 5 t h}$ & $\mathbf{9 0 t h}$ \\
\hline NSE & $-0.45^{* *}$ & $-0.34^{* *}$ & $-0.16^{* *}$ & $-0.09^{* *}$ & $-0.06^{* *}$ \\
& $(0.00)$ & $(0.00)$ & $(0.00)$ & $(0.00)$ & $(0.00)$ \\
\hline $\mathbf{2 5 - 5 5}$ years & $0.11^{* *}$ & $0.14^{* *}$ & $0.19^{* *}$ & $0.2^{* *}$ & $0.06^{* *}$ \\
& $(0.00)$ & $(0.00)$ & $(0.00)$ & $(0.00)$ & $(0.00)$ \\
\hline$>\mathbf{5 5}$ years & $0.08^{* *}$ & $0.08^{* *}$ & $0.13^{* *}$ & $0.13^{* *}$ & $0.06^{* *}$ \\
& $(0.01)$ & $(0.01)$ & $(0.01)$ & $(0.00)$ & $(0.01)$ \\
\hline Primary school & $0.06^{* *}$ & $0.06^{* *}$ & $0.01^{*}$ & $-0.05^{* *}$ & $-0.02^{* *}$ \\
& $(0.01)$ & $(0.00)$ & $(0.00)$ & $(0.00)$ & $(0.00)$ \\
\hline Secondary school & 0.00 & $0.06^{* *}$ & $0.08^{* *}$ & $0.05^{* *}$ & $0.01^{*}$ \\
& $(0.01)$ & $(0.00)$ & $(0.00)$ & $(0.00)$ & $(0.00)$ \\
\hline High school & $0.13^{* *}$ & $0.2^{* *}$ & $0.22^{* *}$ & $0.06^{* *}$ & $-0.02^{* *}$ \\
& $(0.01)$ & $(0.00)$ & $(0.00)$ & $(0.00)$ & $(0.00)$ \\
\hline University and above & $0.13^{* *}$ & $0.25^{* *}$ & $0.41^{* *}$ & $0.54^{* *}$ & $0.17^{* *}$ \\
& $(0.01)$ & $(0.00)$ & $(0.00)$ & $(0.00)$ & $0.00)$ \\
\hline 1-10 years of tenure & $-0.02^{* *}$ & $-0.02^{* *}$ & $0.03^{* *}$ & $0.09^{* *}$ & $0.04^{* *}$ \\
& $(0.00)$ & $(0.00)$ & $(0.00)$ & $(0.00)$ & $(0.00)$ \\
\hline$>\mathbf{1 0}$ years of tenure & $-0.05^{* *}$ & $0.02^{* *}$ & $0.2^{* *}$ & $0.65^{* *}$ & $0.32^{* *}$ \\
& $(0.00$ & $(0.00)$ & $(0.00)$ & $(0.00)$ & $(0.01)$ \\
\hline 1-50 employees & $0.13^{* *}$ & $0.1^{* *}$ & $0.1^{* *}$ & $0.1 * *$ & $0.05^{* *}$ \\
& $(0.00)$ & $(0.00)$ & $(0.00)$ & $(0.00)$ & $(0.00)$ \\
\hline$>\mathbf{5 0}$ employees & $0.12^{* *}$ & $0.1^{* *}$ & $0.13^{* *}$ & $0.2^{* *}$ & $0.1^{* *}$ \\
& $(0.00)$ & $(0.00)$ & $(0.00)$ & $(0.00)$ & $(0.00)$ \\
\hline NSE Selection Term & -0.04 & -0.04 & $-0.04^{*}$ & -0.04 & $-0.1^{*}$ \\
& $(0.03)$ & $(0.02)$ & $(0.02)$ & $(0.05)$ & $(0.04)$ \\
\hline LFP Selection Term & $0.3^{* *}$ & $0.16^{* *}$ & $0.32^{* *}$ & $0.73^{* *}$ & $0.33^{* *}$ \\
& $(0.04)$ & $(0.02)$ & $(0.02)$ & $(0.04)$ & $(0.03)$ \\
\hline Industry & Yes & Yes & Yes & Yes & Yes \\
\hline Occupation & Yes & Yes & Yes & Yes & Yes \\
\hline Region & Yes & Yes & Yes & Yes & Yes \\
\hline Year & 286,453 & 286,453 & 286,453 & 286,453 & 286,453 \\
\hline No of obs. & 0.29 & 0.42 & 0.54 & 0.53 & 0.3 \\
\hline R-Square & & Yes & Yes & Yes & Yes \\
\hline
\end{tabular}

Notes: The reference category is standard employment. UQR models are estimated with bootstrapped standard errors. ** and * denote statistical significance at the .01 and .05 levels, respectively.

Figure 4 summarizes the coefficients on non-standard employment across genders from the UQR estimations. Coefficients at the mean from the OLS regressions are also included for comparison. As can be seen, on average men in Turkey are subject to $12 \%$ of decrease in their 
hourly wages if they are employed in a non-standard job whereas the ratio is around $21 \%$ for women. Moreover, it is clear that atypical employment has much bigger negative effects on female workers at the bottom quantiles. The differences in the wage penalties between men and women at the $10^{\text {th }}$ and $25^{\text {th }}$ quantiles are around $15 \%$, which goes down to $4 \%$ at the $75^{\text {th }}$ quantile and rose slightly to $9 \%$ at the top due to the premium for male workers. In Turkey, women do not have a greater share of non-standard jobs unlike many other European countries, but our findings reveal that they are at a more disadvantaged position with respect to pay. Even after controlling for numerous individual and firm level characteristics as well as industry and occupation, female wages, particularly at the bottom of the distribution, fall considerably if women are employed in atypical positions. These findings hint at gender pay among the non-standard employees, particularly at bottom of the distribution. Even though NSE reduces pay for both genders, women are affected more given the discriminatory practices. Such practices are expected to be higher for atypical employment because legal and collective protection are mostly missing, and this coupled with gender would lead to undervaluation of female work and unfavorable treatment of women in workplaces (Grimshaw, 2011).

Figure 4. Effect of Non-Standard Employment across Quantiles

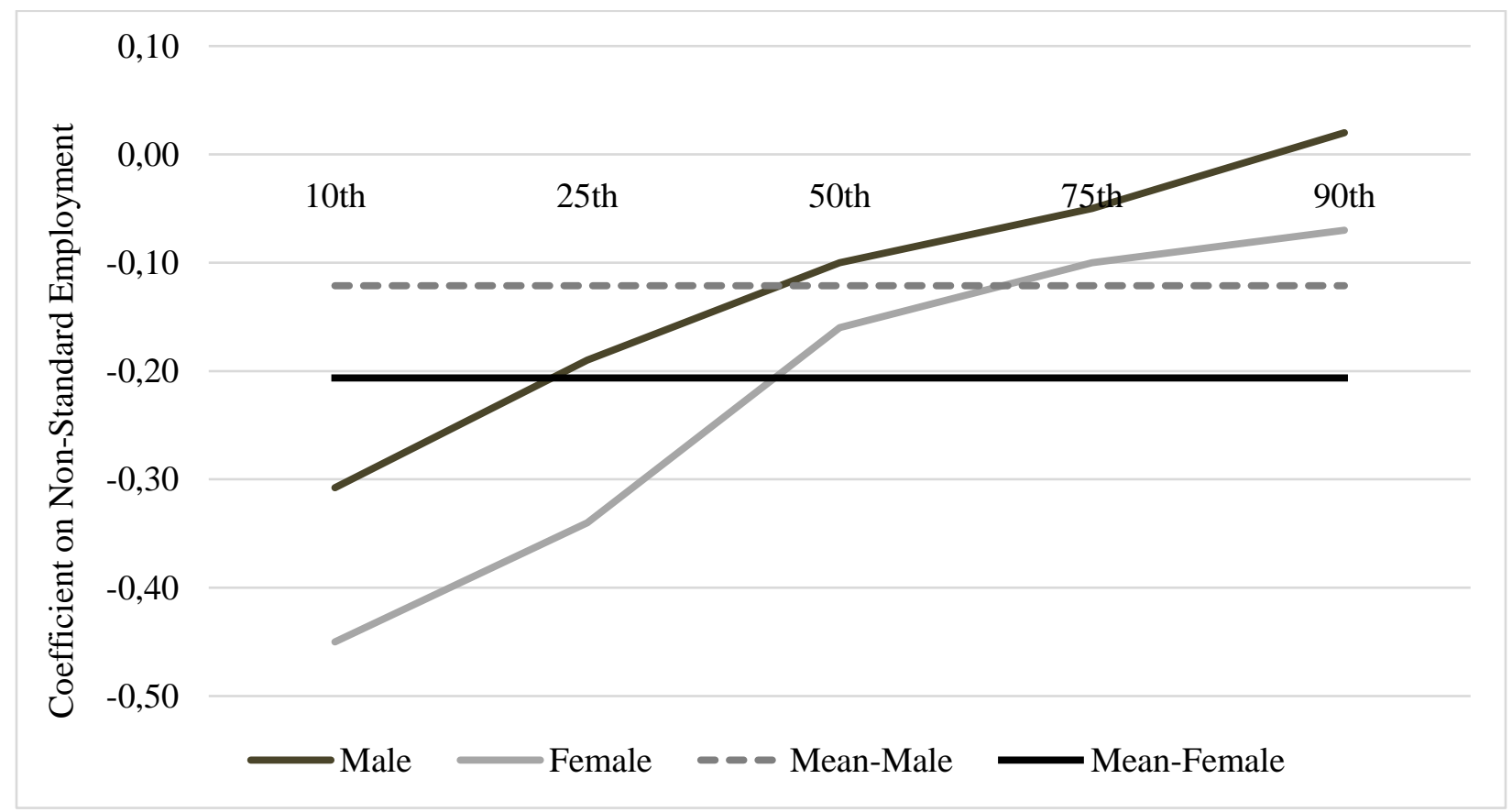

Notes: Based on the unconditional quantile regression results from Table 2 and Table 3 including all control variables and selection terms. The reference category is permanent employment in the formal sector. Mean estimates are obtained from the OLS regressions with all control variables and selection terms. 
Given the differential effects of NSE on wages, we examine the gender pay gap for standard and non-standard employees separately. In Table 4 we show the decomposition of gender pay gap among individuals who have permanent and formal sector jobs. Turkish case turns out to be an outlier from a gender perspective if we solely look at standard employees, since at all quantiles women earn more than men. The estimated wage gap is quite low for the bottom end of the distribution and increases towards the upper end; around $0.04 \log$ points and $0.82 \log$ points respectively. This is primarily due to the higher endowments women hold, and as shown by other studies, gender wage gap at the mean decreases significantly among the university graduates in full-time jobs (Tekguc et al., 2017). Our decomposition results confirm the endowment effect too. More than half of the female-male wage difference at the $10^{\text {th }}$ quantile can be explained by the individual and firm level characteristics and other controls that are included in the above UQR equations. This ratio increases towards the upper end of the distribution and at the $90^{\text {th }}$ quantile; nearly $70 \%$ of the gap is attributable to the variance in the observable features of males and females. The negative signs of the unexplained coefficient in all quantiles suggest that men in Turkish labour market are treated positively. Their characteristics are rewarded more than women and such favourable terms explain $70 \%$ of the wage gap at the bottom of the distribution and $30 \%$ at the top.

Table 4. Decomposition of Gender Pay Gap for Standard Employment

\begin{tabular}{|l|c|c|c|c|c|}
\hline & 10th & 25th & 50th & 75th & 90 $^{\text {th }}$ \\
\hline Difference & $0.04 * *$ & $0.05^{* *}$ & $0.21^{* *}$ & $0.79 * *$ & $0.82^{* *}$ \\
& $(0.003)$ & $(0.002)$ & $(0.007)$ & $(0.01)$ & $(0.02)$ \\
\hline Explained & $0.15^{* *}$ & $0.19^{* *}$ & $0.71^{* *}$ & $1.19^{* *}$ & $1.17 * *$ \\
& $(0.002)$ & $(0.002)$ & $(0.006)$ & $(0.01)$ & $(0.01)$ \\
\hline Unexplained & $-0.1 * *$ & $-0.14 * *$ & $-0.5 * *$ & $-0.4 * *$ & $-0.35^{* *}$ \\
& $(0.003)$ & $(0.003)$ & $(0.006)$ & $(0.01)$ & $(0.01)$ \\
\hline
\end{tabular}

Note: Decompositions are based on RIF-regressions and standard errors are calculated by bootstrapping with 100 replications. ${ }^{* *}$ and $*$ denote statistical significance at the .01 and .05 levels, respectively. Higher earning category is women.

The results for atypical employment in Turkish labour market are in sharp contrast to the above described findings. In Table 5, we present the decomposition results for employees with NSE. As can be observed, women earn less than men at each quantile when we consider the sample of 
atypical employees. The gap is especially large for the bottom and $25^{\text {th }}$ quantile; around 0.32 and $0.28 \log$ points respectively. While the gap slightly declines to $0.18 \log$ points at the top, still nonstandard female employees earn much less than their male counterparts. When we look at the explained component of the pay gap, for the bottom quantiles, they don't capture much of the variance even though the coefficients are statistically significant. For example, at the $10^{\text {th }}$ quantile the observable characteristics account for less than $14 \%$ of the wage difference across gender. Only at the $90^{\text {th }}$ quantile, the explained part captures nearly $50 \%$ of the pay gap but its sign remains to be negative. When we look at the unexplained component, it becomes visible that returns to female employee's attributes at the bottom end of the distribution are well below than what the males obtain in the labor market. For example, more than $85 \%$ of the wage differences can be captured by the returns to the characteristics of female workers at the $10^{\text {th }}$ quantile. However, the unexplained part of gender pay gap decreases as we move towards the upper end of the distribution. For the top earners, $90^{\text {th }}$ quantile, the coefficient on returns almost explains $50 \%$ of the gap suggesting that there is less discrimination against higher skilled female workers with NSE in Turkey.

Table 5. Decomposition of Gender Pay Gap for Non-Standard Employment

\begin{tabular}{|l|c|c|c|c|c|}
\hline & 10th & 25th & 50th & 75th & 90 $^{\text {th }}$ \\
\hline Difference & $0.32^{* *}$ & $0.28^{* *}$ & $0.22^{* *}$ & $0.25^{* *}$ & $0.18^{* *}$ \\
& $(0.004)$ & $(0.003)$ & $(0.004)$ & $(0.006)$ & $(0.01)$ \\
\hline Explained & $-0.05^{* *}$ & $-0.05 * *$ & $-0.04 * *$ & $-0.04^{* *}$ & $-0.2^{* *}$ \\
& $(0.005)$ & $(0.003)$ & $(0.004)$ & $(0.006)$ & $(0.01)$ \\
\hline Unexplained & $0.37 * *$ & $0.33 * *$ & $0.26 * *$ & $0.34 * *$ & $0.38^{* *}$ \\
& $(0.004)$ & $(0.004)$ & $(0.004)$ & $(0.007)$ & $(0.01)$ \\
\hline
\end{tabular}

Note: Decompositions are based on RIF-regressions and standard errors are calculated by bootstrapping with 100 replications. $* *$ and $*$ denote statistical significance at the .01 and .05 levels, respectively. Higher earning category is men.

Women both in typical and atypical jobs hold greater endowments in the Turkish labor market. Yet, for the non-standard female employees having advantageous individual or workplace characteristics do not lower the pay gap sufficiently. As can be seen from the results, the unexplained component has the greatest explanatory power for the gender wage gap among nonstandard employees in Turkey. While the observable differences in education, occupation and 
work history slightly reduce the wage differences between male and female non-standard employees, the returns to these characteristics are considerably lower for women. This is in line with other studies presenting that the unexplained part of gender pay gap increases despite the improvements in female endowments over time (Blau and Kahn 2017; Meurs and Ponthieux, 2015). Especially for the workers in the bottom end of the distribution, unexplained component is mainly responsible for the differences in wages across genders. Women are discriminated in standard jobs as well, but the impact is much larger for the employees in atypical positions. As discussed in the earlier sections, this is due to lack of legal and institutional protection or undervaluation of women's work. Besides, bargaining power and exit options of female employees in low-paid and non-standard jobs are considerably low, which raise the possibility of discrimination.

\section{Conclusion}

Gender pay gap and its persistence even under the new political and legislative conditions that aim to foster gender equality remain to be one of the most widely studied topics across many disciplines. Our paper extends the literature by investigating the effect of NSE on the wages of men and women in Turkey and how it shapes gender pay gap. Research on Turkey is relatively scarce and focusing on the Turkish case would add to our understanding of the relationship between employment categories and gender inequalities in several ways. First, there are various emerging economies that have similarly low share of temporary and part-time work and high share of informal sector employment. Besides, traditional gender roles in a number of developing countries are extremely strict like in Turkey, which leads to low levels of labor force participation especially among the unskilled. Hence, our findings can be illustrative for other developing countries with similar allocation of non-standard jobs across genders and adverse perceptions of female work. The findings revealed that atypical jobs reduce female wages at a greater rate and gender wage gap is considerable among non-standard employees. Moreover, our results indicate that women in Turkey have higher level of endowments but the returns to these endowments are significantly below the male ones, particularly for bottom end of employees in NSE. These show that low-paid female workers in non-standard jobs face higher discrimination in Turkish labor market, and hence employment types are explanatory for gender inequalities. Although, the growth 
of NSE can raise the employment rates for various disadvantaged groups including women, the negative effects of such jobs need to be taken into account when policies are designed.

In addition to the widely studied policy recommendations of regulation and enforcement of equal pay, we argue that employment protection legislation should take gender aspects into consideration and have stricter restrictions on non-standard contracts for potentially disadvantaged groups. As our results highlight NSE is detrimental to the earnings of women along the distribution, and particularly for the bottom earners. Such jobs potentially decrease the skill investments and effort levels given the low pay and lack of protection, which could significantly hurt productivity and growth rates. Hence, making contracts securer and accommodating them with proper income and labor market policies can boost productivity and job creation at the macro level. Moreover, schemes that facilitate smoother transitions to standard employment and reduce interruptions in female work histories to be an effective way of reducing negative effects of nonstandard contracts. However, it should be noted that cross-sectional data doesn't allow us to pinpoint if pay inequalities and disadvantages of women can be explained by career interruptions. Also, we are unable to test if there are additional risks of NSE for women such as unemployment and lower rates of transition to standard jobs. Lastly, in labor markets that are largely segmented with well-protected and well-paid jobs on the one hand, and informal sector jobs, on the other, de jure measures of employment protection become less relevant. Since informal sector workers are not covered by the legislation, a sizable part of employees including females, are left with little or no protection. Hence, easing social security eligibility requirements and extending employment protection legislation to all workers can improve the working conditions of women. 


\section{References}

Acar, E.O. and Tansel, A. (2016), "Defining and Measuring Informality: The Case of Turkish Labor Market”. Sosyoekonomi, 24(28), pp. 147-174.

Aktas, A. and Uysal, G. (2016), "The gender wage gap in Turkey", MU Iktisadi ve Idari Bilimler Dergisi, 38(2), pp. 1-19.

Blau, F. and Kahn, L. (2017), “The Gender Wage Gap: Extent, Trends, and Explanations”, Journal of Economic Literature, 55(3), pp. 789-865.

Boll, C., Rossen, A. and Wolf, A. (2017), “The EU Gender Earnings Gap: Job Segregation and Working Time as Driving Factors”, Journal of Economics and Statistics, 237(5), pp. 407452.

Booth, A., Francesconi, M. and Frank, J. (2002), “Temporary jobs: Stepping stones or dead ends?", Economic Journal, 112(480), pp. 189-213.

Booth, A. and Leigh, A. (2010), "Do employers discriminate by gender? A field experiment in female-dominated occupations", Economic Letters, 107(2), pp. 236-238.

Bosio, G. (2014), “The Implications of Temporary Jobs on the Distribution of Wages in Italy: An Unconditional IVQTE Approach”, Labour, 28(1), pp. 64-86.

Buchinsky, M. (1998), "The dynamics of changes in the female wage distribution in the USA: a quantile regression approach", Journal of Applied Econometrics, 13, pp. 1-30.

Cazes, S. and de Laiglesia, J.R. (2015) “Temporary contracts and wage inequality”. In J. Berg (ed.), Labour Markets, Institutions and Inequality: Building Just Societies in the 21st Century, Cheltenham: Edward Elgar, pp. 147-183. 
Cudeville, E. and Gurbuzer, L.Y. (2010), “Gender Wage Discrimination in the Turkish Labor Market: Can Turkey Be Part of Europe?", Comparative Economic Studies, 52(3), pp. 429463.

Duguet, E. and Petit, P. (2005), "Hiring Discrimination in the French Financial Sector: An Econometric Analysis on Field Experiment Data", Annales de'Economie et de Statistique, 78, pp. 79-102.

Duman, A. (2019), "Wage Penalty for Temporary Workers in Turkey: evidence from quantile regressions", Developing Economies, 54(4), pp. 283-310.

Duman, A. (2014), "Labor Market Institutions, Policies, and Performance: flexibility and security in Turkey", EAF Report, No. 14-01.

Eichhorst, W. and Marx, P. (eds.) (2015), Non-standard Employment in Post-industrial Labour Markets: An Occupational Perspective, Cheltenham: Edward Elgar.

Firpo, S., Fortin, N., and Lemieux, T. (2009), "Unconditional Quantile Regressions", Econometrica, 77(3), pp. 953-973.

Fortin, N., Lemieux, T. and Firpo, S. (2011), "Decomposition methods in Economics", Handbook of Labor Economics, Vol, 4a, pp. 1-102.

Fuller, S. and Vosko, L.F. (2008), “Temporary Employment and Social Inequality in Canada: Exploring Intersections of Gender, Race and Immigration Status", Social Indicators Research, 88(1), pp. 31-50.

Garnero, A., Giuliano, R., Mahy, B. and Rycx, F. (2016), "Productivity, wages and profits among Belgian firms: do fixed-term contracts matter?", International Journal of Manpower, 37(2), pp. 303-322. 
Gash, V. and McGinnity, F. (2007), "Fixed-Term Contracts-The New European Inequality? Comparing Men and Women in West Germany and France". Socio-Economic Review, 5(3), pp. 467-496.

Grimshaw, D. (2011), "What Do We Know about Low-Wage Work and Low-Wage Workers? Analysing the Definitions, Patterns, Causes and Consequences in International Perspective". ILO Working Paper, No. 28.

Heckman, J.J. (1979), “Sample Selection Bias as a Specification Error”. Econometrica, 47, pp. $153-161$.

Heim, B.T. (2007), "The Incredible Shrinking Elasticities: Married Female Labor Supply, 1978-2002”. Journal of Human Resources, 42(4), pp. 881-918.

Ilkkaracan, I. and Selim, R. (2007), "The gender wage gap in the Turkish labor market", Labour, 21(3), pp. 563-593.

ILO (2016), Non-Standard Employment Around the World. Geneva: ILO.

Kahn, L. (2016), "The Structure of the Permanent Job Wage Premium: Evidence from Europe". Industrial Relations, 55(1), pp. 149-178.

Kaya, E. (2019), "Gender wage gap across the quantiles: What is the role of firm segregation?", Cardiff Economics Working Papers, No. E2019/7.

Kurz, K. (2002), "Fixed-term contracts and unemployment at the beginning of the employment career in Germany: does gender matter?". In E. Ruspini and A. Dale (eds). The Gender Dimension of Social Change. The Contribution of Dynamic Research to the Study of Women's Life Courses. Bristol: Policy, pp. 133-157. 
Lass, I. and Wooden, M. (2019), "The Structure of the Wage Gap for Temporary Workers: Evidence from Australian Panel Data”, British Journal of Industrial Relations, 57(3), pp. 453478.

Meurs, D. and Ponthieux, S. (2015), “Gender Inequality”, Handbook of Income Distribution, Vol. 2, pp. 983-1119.

OECD. (nd), Gender Wage Gap, Retrieved from https://stats.oecd.org/index.aspx?queryid=54751, on 30 April 2020.

Petrongolo, B. (2004), “Gender Segregation in Employment Contracts”. Journal of the European Economic Association, 2(2-3), pp. 331-345.

Picchio, M. (2006), "Wage Differentials between Temporary and Permanent Workers in Italy", Quaderni di Ricerca Working Paper, No. 257.

Tekguc, H., Eryar, D. and Cindoglu, D. (2017), “Women's Tertiary Education Masks the Gender Wage Gap in Turkey", Journal of Labour Research, 38, pp. 360-386.

TUIK. (nd), İş Gücü İstatistikleri, Retrieved from https://biruni.tuik.gov.tr/medas/?kn=72\&locale=tr, on 30 April 2020.

Vosko, L., MacDonald, M. and Campbell, I. (2009), Gender and the contours of precarious employment. London: Routledge. 
Appendix

Table A1. Summary Statistics of Variables

\begin{tabular}{|l|c|c|c|c|c|}
\hline & Observation & Mean & Std. Dev. & Min & Max \\
\hline Hourly real wages (In) & $1,138,940$ & 2.01 & 0.60 & 0.01 & 7.53 \\
\hline NSE & $1,138,940$ & 0.25 & 0.43 & 0.00 & 1.00 \\
\hline Age & $1,138,940$ & 35.24 & 10.65 & 15.00 & 100.00 \\
\hline Gender & $1,138,940$ & 0.25 & 0.43 & 0.00 & 1.00 \\
\hline Primary school & $1,138,940$ & 0.28 & 0.45 & 0.00 & 1.00 \\
\hline Secondary school & $1,138,940$ & 0.17 & 0.38 & 0.00 & 1.00 \\
\hline High school & $1,138,940$ & 0.25 & 0.43 & 0.00 & 1.00 \\
\hline University and above & $1,138,940$ & 0.25 & 0.44 & 0.00 & 1.00 \\
\hline Tenure & $1,138,809$ & 6.49 & 7.67 & 0.00 & 65.00 \\
\hline 10-50 employees & $1,138,940$ & 0.38 & 0.48 & 0.00 & 1.00 \\
\hline$>$ 50 employees & $1,138,940$ & 0.28 & 0.45 & 0.00 & 1.00 \\
\hline Mining and Quarrying & $1,138,940$ & 0.12 & 0.33 & 0.00 & 1.00 \\
\hline Manufacturing & $1,138,940$ & 0.10 & 0.30 & 0.00 & 1.00 \\
\hline Construction & $1,138,940$ & 0.03 & 0.18 & 0.00 & 1.00 \\
\hline Wholesale and Retail Trade & $1,138,940$ & 0.24 & 0.42 & 0.00 & 1.00 \\
\hline Transportation and Storage & $1,138,940$ & 0.07 & 0.26 & 0.00 & 1.00 \\
\hline Financial and Insurance Activities & $1,138,940$ & 0.04 & 0.19 & 0.00 & 1.00 \\
\hline $\begin{array}{l}\text { Professional, Scientific and } \\
\text { Technical Activities }\end{array}$ & $1,138,940$ & 0.02 & 0.13 & 0.00 & 1.00 \\
\hline $\begin{array}{l}\text { Public Administration and Defence; } \\
\text { Compulsory Social Security }\end{array}$ & $1,138,940$ & 0.30 & 0.46 & 0.00 & 1.00 \\
\hline Other Service Activities & $1,138,940$ & 0.04 & 0.21 & 0.00 & 1.00 \\
\hline Professional & $1,138,940$ & 0.13 & 0.33 & 0.00 & 1.00 \\
\hline $\begin{array}{l}\text { Technicians and associate } \\
\text { professionals }\end{array}$ & $1,138,940$ & 0.09 & 0.28 & 0.00 & 1.00 \\
\hline Clerical support workers & $1,138,940$ & 0.10 & 0.30 & 0.00 & 1.00 \\
\hline Service and sales workers & $1,138,940$ & 0.18 & 0.39 & 0.00 & 1.00 \\
\hline $\begin{array}{l}\text { Skilled agricultural, forestry and } \\
\text { fishery workers }\end{array}$ & $1,138,940$ & 0.01 & 0.10 & 0.00 & 1.00 \\
\hline Craft and related trades workers & $1,138,940$ & 0.16 & 0.37 & 0.00 & 1.00 \\
\hline $\begin{array}{l}\text { Plant and machine operators, and } \\
\text { assemblers }\end{array}$ & $1,138,940$ & 0.13 & 0.34 & 0.00 & 1.00 \\
\hline Elementary occupations & $1,138,940$ & 0.16 & 0.36 & 0.00 & 1.00 \\
\hline & & & & & \\
\hline
\end{tabular}


Figure A1. Hourly Wage Distribution among Non-Standard Employees

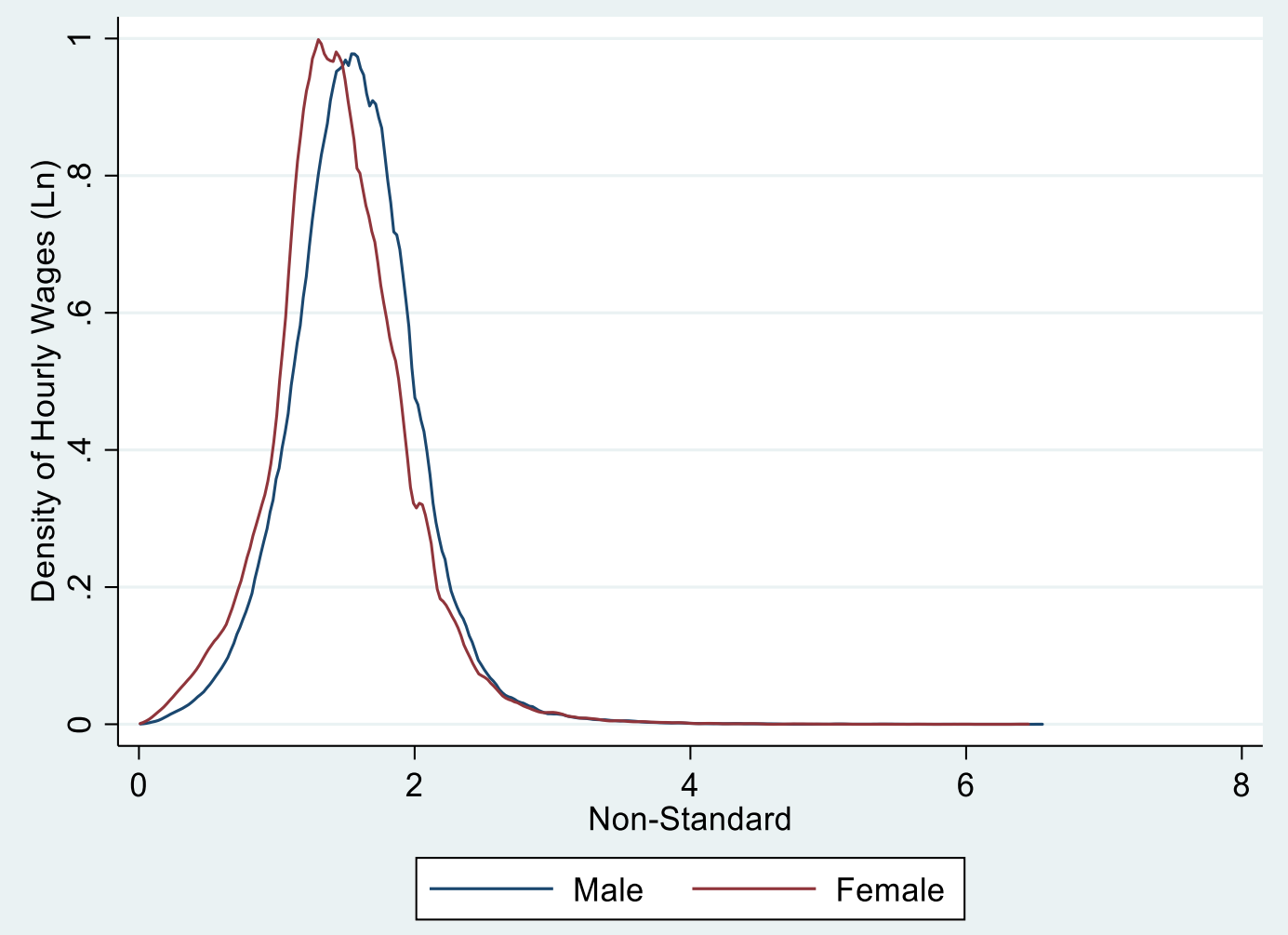


Table A1. Robustness Checks on Effect of Contract Type - Males

\begin{tabular}{|l|c|c|c|}
\hline & $\begin{array}{c}\text { Without } \\
\text { Selection }\end{array}$ & $\begin{array}{c}\text { Private } \\
\text { Sector }\end{array}$ & $\begin{array}{c}\text { Non-Agriculture } \\
\text { Sectors }\end{array}$ \\
\hline 10th & $-0.31^{* *}$ & $-0.39^{* *}$ & $-0.42^{* *}$ \\
& $(0.00)$ & $(0.00)$ & $(0.00)$ \\
\hline 25th & $-0.19^{* *}$ & $-0.2^{* *}$ & $-0.23^{* *}$ \\
& $(0.00)$ & $(0.00)$ & $(0.00)$ \\
\hline 50th & $-0.1^{* *}$ & $-0.08^{* *}$ & $0.058^{* *}$ \\
& $(0.00)$ & $(0.00)$ & $(0.00)$ \\
\hline 75th & $-0.05^{* *}$ & $0.005^{*}$ & $-0.06^{* *}$ \\
& $(0.00)$ & $(0.00)$ & $(0.00)$ \\
\hline 90th & $0.02^{* *}$ & $0.05^{* *}$ & $0.01^{* *}$ \\
& $(0.00)$ & $(0.00)$ & $(0.00)$ \\
\hline Individual Controls & Yes & Yes & Yes \\
\hline Firm-Level Controls & Yes & Yes & Yes \\
\hline Industry & Yes & Yes & Yes \\
\hline Occupation & Yes & Yes & Yes \\
\hline Region & Yes & Yes & Yes \\
\hline Year & Yes & Yes & Yes \\
\hline Number of & 852,356 & 471,159 & 820,523 \\
Observations & & & \\
\hline
\end{tabular}

Notes: The reference category is permanent employment. UQR models are estimated with bootstrapped standard errors. ** denote statistical significance at the .01 level. * denote statistical significance at the .05 level. 
Table A2. Robustness Checks on Effect of Contract Type - Females

\begin{tabular}{|l|c|c|c|}
\hline 10th & $\begin{array}{c}\text { Without } \\
\text { Selection }\end{array}$ & $\begin{array}{c}\text { Private } \\
\text { Sector }\end{array}$ & $\begin{array}{c}\text { Non-Agriculture } \\
\text { Sectors }\end{array}$ \\
\hline 25th & $-0.45^{* *}$ & $-0.7^{* *}$ & $-0.7^{* *}$ \\
& $(0.00)$ & $(0.00)$ & $(0.00)$ \\
\hline 50th & $-0.34^{* *}$ & $-0.4^{* *}$ & $-0.4^{* *}$ \\
& $(0.00)$ & $(0.00)$ & $(0.00)$ \\
\hline 75th & $-0.16^{* *}$ & $-0.15^{* *}$ & $-0.16^{* *}$ \\
& $(0.00)$ & $(0.00)$ & $(0.00)$ \\
\hline 90th & $-0.1^{* *}$ & $-0.04^{* *}$ & $-0.1^{* *}$ \\
& $(0.00)$ & $(0.00)$ & $(0.00)$ \\
\hline Individual Controls & $-0.07^{* *}$ & $-0.03^{* *}$ & $-0.09^{* *}$ \\
\hline Firm-Level Controls & $(0.00)$ & $(0.00)$ & $(0.00)$ \\
\hline Industry & Yes & Yes & Yes \\
\hline Occupation & Yes & Yes & Yes \\
\hline Region & Yes & Yes & Yes \\
\hline Year & Yes & Yes & Yes \\
\hline Number of & Yes & Yes & Yes \\
Observations & 286,453 & 148,042 & Yes \\
\hline
\end{tabular}

Notes: The reference category is permanent employment. UQR models are estimated with bootstrapped standard errors. ** denote statistical significance at the .01 level. * denote statistical significance at the .05 level. 
${ }^{\mathrm{i}}$ Atypical and non-standard are used interchangeably throughout the paper.

ii Female labour force participation was nearly 28\% for the period between 2005 and 2017 while male labour force participation was $70 \%$ over the same years (OECD, nd).

iii Informal sector employment among men went down from $30.37 \%$ in 2005 to $14.6 \%$ in 2017 whereas the same ratios were $32 \%$ and $18.5 \%$ for women over the period. While the share of temporary contracts (from $11.7 \%$ in 2005 to $10.8 \%$ in 2017 for men and $11.7 \%$ to $9.7 \%$ for women) and part-time employment (from $1.5 \%$ in 2005 to $2.6 \%$ in 2017 for men and $5.6 \%$ to $7.6 \%$ for women) for both genders remain relatively stable.

iv The median wage gap in Turkey was around $6.9 \%$ while the OECD average was $14 \%$ in 2014. Gender wage gap is unadjusted and defined as the difference between median wages of men and women relative to the median wages of men.

${ }^{v}$ Turkish Statistical Institute (TUIK) releases micro data both annually and quarterly. For details on sampling and quality, please see

http://www.turkstat.gov.tr/jsp/duyuru/upload/qualityreports/surveys/HouseholdLabourForceSurvey.zip.

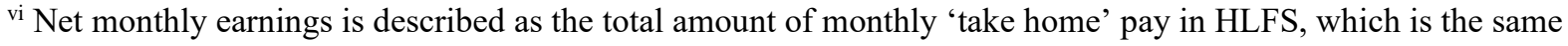
wording used in European Labour Force Surveys.

${ }^{\text {vii }}$ HLFS in Turkey does not distinguish between different types of temporary employment such as seasonal, agency or fixed-term.

viii Currently, informal employment is recognized as employment without social security in the main job during the reference week by the Turkish Statistical Institute (TUIK, nd). It has been argued that social security criterion better captures informality in Turkey than enterprise criterion, and it is able to explain the relationship between the likelihood of informal sector employment, individual and job characteristics (Acar and Tansel, 2015).

ix Additionally, we include dummy variables for industry according to NACE-Rev2 classification, dummy variables for occupation at the ISCO-08 2 digit level, dummy variables for regions at NUTS-1 level and dummy variables for the survey years.

${ }^{x}$ To test for sensitivity to model specification, the square of inverse Mill's ratio and its third power are also employed in the regressions for robustness.

xi The results for non-standard employment from the models without selection terms are provided in the Appendix. Full results can be obtained from the author upon request.

${ }^{\text {xii }}$ We ran the RIF regressions by using the private sector employees only and by excluding the workers in agricultural sector. Full results can be obtained from the author upon request. 